\title{
Stiffness Modulus of Asphaltic Concrete Incorporating Coir Fibre and Subjected to Aging
}

\author{
Abdullahi Ali Mohammed ${ }^{1}$, Ramadhansyah Putra Jaya ${ }^{2 *}$, Étienne Joseph Marie Delbrel ${ }^{1}$, \\ Choong Wee Kang ${ }^{1}$, Sien Ti Kok ${ }^{1}$, Haryati Yaacob ${ }^{3}$, Norhidayah Abdul Hassan ${ }^{3}$, Nor \\ Hayati Abdul Hamid ${ }^{4}$ and Noram Irwan Ramli ${ }^{2}$ \\ ${ }^{1}$ Facutly of Engineering, University of Nottingham, Malaysia Campus, Jalan Broga, 43500 Semenyih, \\ Selangor, Malaysia \\ ${ }^{2}$ Faculty of Civil Engineering and Earth Resources, Universiti Malaysia Pahang, 26300 Gambang, \\ Pahang, Malaysia \\ ${ }^{3}$ Faculty of Engineering, School of Civil Engineering, Universiti Teknologi Malaysia, 81310 UTM \\ Skudai, Johor Bahru, Malaysia \\ ${ }^{4}$ Institute for Infrastructure Engineering and Sustainable Management (IIESM), Universiti Teknologi \\ MARA, 40450 Shah Alam, Selangor, Malaysia
}

\begin{abstract}
The aim of this paper is to investigate the performance response of a set of coir fibre modified asphalt samples subjected different ageing conditions and containing three different fibre contents. The laboratory experimental programs are indirect tensile test at $25^{\circ} \mathrm{C}$ and repeated load axial test at $40^{\circ} \mathrm{C}$. The results showed that the fibres improved the mixture's performance. The main findings obtained at $25^{\circ} \mathrm{C}$ for short and long-term ageing reveal that low fibre content at around $0.3 \%$ per aggregate weight display a stiffness modulus up to $14 \%$ higher than that of unmodified mixtures, hence showing that fibres may improve the bearing capacity and rut-resistance of asphalt mixtures. Conversely, as the amount of fibre increases to $0.5 \%$ and $0.7 \%$, the stiffness decreases to the point of becoming unacceptably low, almost $80 \%$ lower than unmodified mixes stiffness. However the data also reveal that high fibre contents at $0.5 \%$ and above completely neutralize the impact of ageing on the mixture, indicating that fibre-modified mixtures would yield longer lives.
\end{abstract}

\section{Introduction}

Countries around the world face challenges to maintain their existing road networks due to increase in traffic loading density in terms of numbers of axles and high tyre pressures resulting from heavy vehicles, places great demand on the existing road network [1]. Conventional bitumen is widely used in most countries hardens at the early stages during handling, mixing and in service. The level of pavement performance has a close relationship with the properties of bitumen used. This rheological weakness of the

\footnotetext{
* Corresponding author: ramadhansyah@ump.edu.my
} 
conventional bitumen has generated an increasing interest in the use of modifiers to enhance properties of conventional bitumen. Modifiers vary in function and effectiveness, and development of modified bituminous material to improve the overall performance of pavements has been the focus of research for the past few decades. Among additives used to improve pavement materials are fibres, synthetic or natural, which are used to create a network of tension-resisting strings within the mixture [2]. Coir fibre is an organic material extracted from the coconut husk [3]. Fibres in general can be produced from a great number of virgin or recycled materials such as polyester, asbestos, glass, polypropylene, carbon, cellulose or solid wastes such as bamboo, coconut, date palm, and oil palm, [4]. The addition of coir fibre in asphaltic mixtures enhances properties such as material strength, stability, durability, resistance to permanent deformation, ductility and compressibility as reported by [5]. Thulasirajan and Narasimha [6] found that air voids of the mix are directly proportional to the fibre content, but behaves differently with fibre length. More precisely, the volume of air voids initially decreases with length to reach a minimum at a fibre length around $13.5 \mathrm{~mm}$, but then increases again as fibres get longer. Ting et al. [7] recommends using $17.25 \mathrm{~mm}$ long fibres at $0.46 \%$ content along with $5 \%$ bitumen content. It must be noted that in both studies the recommended content percentage values for the fibre are rather small. Ramadhansyah et al. [8] reported that replacing filler in the mix with coconut powder may also reduce the pozzolanic properties of the mix as compared to quarry dust, hence reducing its strength. Besides coconut husk, engineers have explored a wide range of potential organic materials to serve for fibre modification [9]. For example, Shao Peng et al. [10] reported on the viscosity, rheological, dynamic and fatigue properties of bituminous mixes containing polyester fibres. Chen and Lin [11] reported that good adhesion between fibres and the binder enhances the load-carrying ability of asphalt-fibre mastics.

\section{Material and methods}

\subsection{Material and methods}

\subsubsection{Materials}

The coir or coconut fibre is extracted from the husk of disposed-off ripe coconut shells, which are harvested from the Cocos-nucifera palm trees. The bitumen used is $80 / 100$ penetration grade. Physical properties of material used as shown in Table 1. In order to further reduce the number of independent variables, bitumen percentage content used throughout this experiment is to remain fixed at $5 \%$ of the aggregate weight. The type of aggregate involved in the casting of those samples is granite, both coarse and fine, under the form of quarry dust. Aggregate gradation is defined as per JKR ACW14 [12] specifications as shown in Fig. 1. 
Table 1. Physical properties of material used

\begin{tabular}{rcc}
\hline Property & Measured Parameter & Values \\
\hline $\begin{array}{r}\text { Bitumen } \\
(80 / 100)\end{array}$ & Relative Density & 1.02 \\
& Softening Point $\left({ }^{\circ} \mathrm{C}\right)$ & 44.0 \\
& Penetration at $25^{\circ} \mathrm{C}(\mathrm{dmm})$ & 83 \\
Aggregate & Ductility $(\mathrm{cm})$ at $25^{\circ} \mathrm{C}$ & $>100$ \\
\hline & Specific Gravity & 2.681 \\
\hline Cement & Specific Gravity & 3.018 \\
\hline
\end{tabular}

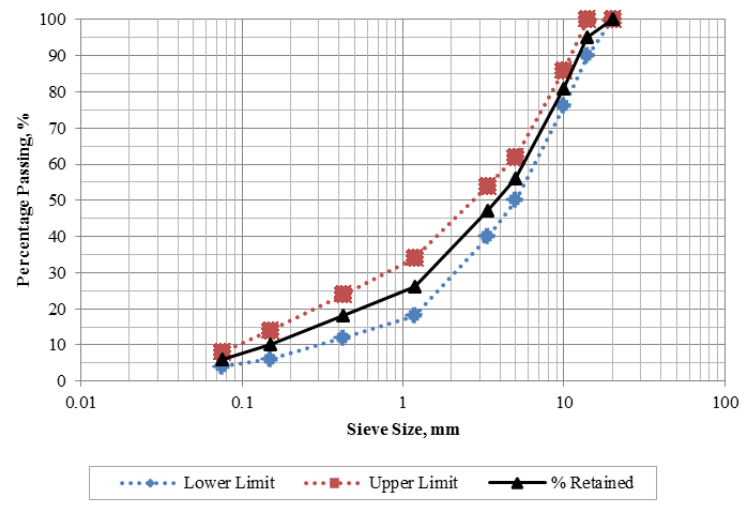

Fig. 1. Aggregate gradation used in this study [12]

\subsection{Ageing procedure}

The mix ageing procedure adopted here is based on Strategic Highway Research Program procedure as described in AASHTO R30-02 [13]. Separate specimens were prepared at the time of mixing to represent an un-aged condition. Their preparation was identical as for the other specimens but not subjected to conditioning. As soon as mixing was complete, the specimens were then compacted using a gyratory compactor. The short-term conditioning for the mixture mechanical property testing procedure applies to laboratory-prepared, loose mix only. The mixture was placed in a pan, and spread it to an even thickness ranging between 25 and $50 \mathrm{~mm}$. the mixture were placed in a forced-draft oven for $4 \mathrm{~h} \pm 5 \mathrm{~min}$. at a temperature of $135 \pm 3^{\circ} \mathrm{C}$. Long term mixture conditioning procedure can be applied to laboratory-prepared samples following short term aging, to plant-mixed HMA, or to compact roadway samples when needed to simulate long term aging effects. The procedure was carried out on compacted specimens after they have been short-term aged. The specimens were placed in a forced-draft oven in two different stages, the first stage the samples were pre-heated to $85^{\circ} \mathrm{C}$ temperature and left for five days. The specimens were then removed from the oven and are tested within 24 hours. 


\subsection{Stiffness modulus test}

This investigation principally rests on the results obtained from a 5-pulse repeated Indirect Tensile Test, as it provides essential information in a short amount of time, such as the fatigue behaviour, the deformation rate and the stiffness modulus of the material. A load pulse is applied along the vertical diameter, and the peak horizontal transient deformation is measured. The specimens are 100 to $150 \mathrm{~mm}$ in diameter and possess a thickness ranging between 30 and $80 \mathrm{~mm}$. For this investigation, the test method shall be as per ASTM D7369-11 [14], where only the horizontal LVDTs set in the diameter axis are recorded. This test is carried out by a MATTA machine, or Nottingham Asphalt Tester (NAT). The sample as subjected to a minimum of 4 hours of preconditioning at $25 \pm 0.5^{\circ} \mathrm{C}$ immediately before the testing session.

\subsection{Repeated load axial test}

In this test an unconfined cylindrical specimen is subjected to axial stress pulses of 1 second duration and magnitude $100 \mathrm{kPa}$ separated by 1 second rest periods. The deformation is measured by the change in distance between the loading platens throughout the test. This is monitored and recorded by 2 diametrically positioned displacement transducers resting on the upper platen. Both axial strain and axial strain rate are noted at completion of the test. The test duration is normally 1800 load pulses and it is carried out at a constant temperature.

\section{Results and discussion}

\subsection{Stiffness modulus}

Fig. 2 can be observed that two ranges of stiffness modulus behavior emerge despite the difference in fiber content. The temperature measured test specimen was similar for both mixtures. In the first category, addition of $0.3 \%$ fiber content results overall in slightly higher stiffness in both the short and long-term stages as compared to the samples containing no fiber. The $0.3 \%$ specimens achieve a resilient modulus of $1130 \mathrm{MPa}$, whereas the unmodified samples fall slightly short of $1000 \mathrm{MPa}$. The difference is even more obvious at the long-term ageing stage, where the stiffness of the fiber modified specimens soars to reach $2070 \mathrm{MPa}$, whilst that of the unmodified samples do not cross $1850 \mathrm{MPa}$. In comparison, the $0.5 \%$ and $0.7 \%$ samples are completely outclassed in terms of strength, achieving only $715 \mathrm{MPa}$ and $393 \mathrm{MPa}$ respectively at their best. This suggests that low fiber inclusion improves the stiffness of the mix, allowing for better load-spreading and rutresistance, whereas high amounts of fiber significantly reduce it, making it impractical for use. It is also very obvious that fiber inclusion dramatically reduces the impact of shortterm ageing on the specimens. At control sample, the drop in stiffness is both extremely important and sudden, whereas the $0.3 \%$ set undergoes only a very small change from unaged to short-term ageing, a change which is actually an increase. 


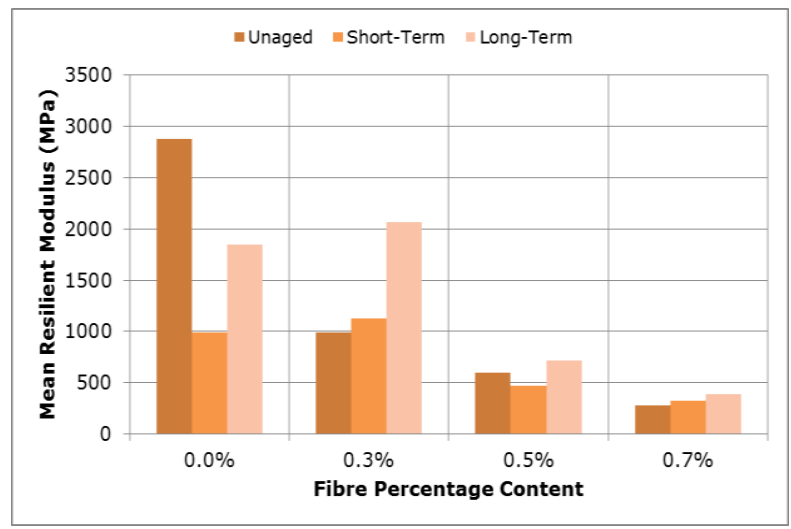

Fig. 2. Stiffness Modulus at different Fibre Content

\subsection{Stiffness modulus at different aging}

The percentage difference between unaged, short and long term stiffness may still be noticeable, but the range it covers is much smaller as compared to the first category as shown in Fig. 3. It remains less than $250 \mathrm{MPa}$ for both the $0.5 \%$ and $0.7 \%$ samples against more than $1000 \mathrm{MPa}$ for the $0.3 \%$ specimen. Therefore, coir fibres do affect the ageing behaviour proportionally to the level of modification. Inversely, a soft mixture would be harder to crack, but less resistant to rutting and permanent deformation. Considering the fact that this test has been carried out in relatively low temperature conditions, at $25^{\circ} \mathrm{C}$, there is prospect that fibre inclusion will allow the stiffness to be better controlled in cool climates, where the mixture strength is critical as low temperatures would naturally stiffen the pavement materials. Fibre modification would hence not only adjust the stiffness at a level where brittle failure, but it would also reduce the effect of hardening over time due to low susceptibility to ageing [15].

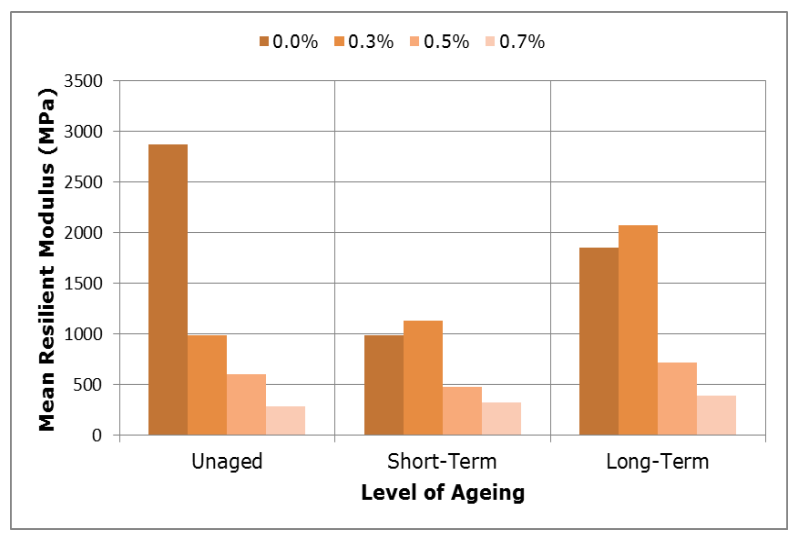

Fig. 3. Stiffness Modulus vs. Level of Ageing

\subsection{Stiffness modulus versus service life}

Fig. 4 shows the evolution in stiffness behaviour of the different asphalt mixture throughout a service life ranging from the moment it comes out of the mixing plant until 10 years after. It can be observed that all fibre-modified mixtures display a fairly consistent trend with an 
overall increase in stiffness with time. This trend is more obvious at higher fibre contents, whereas there is little to almost no change for lower percentages. This not only confirms that fibre inclusion considerably reduces the impact of short-term ageing, but it also shows that if the level of modification is high enough, the long-term impact on the stiffness also remains insignificant. This means that the modified bituminous mixtures are expected to yield longer lives due to much better ageing. However, this advantage comes at the expense of the material strength which is dangerously low, making it a useless mixture. This property of fibre-modified asphalts should nevertheless be investigated for application in sub-zero temperatures, where the resultant hardening due to extreme cold weather may cater for the lack of strength, but without the risk of the pavement stiffening too much and hence cracking over time. Now when observing the case of the unmodified asphalt mix, it is interesting to notice the sudden drop of its strength in the first half of the graph, between the time it comes out of the mixing stage until it is laid. In comparison, the $0.3 \%$ sample experiences instead a slight increase in strength of about $15 \%$, indicating that storing, hauling and paving delays for fibre-modified mixtures are not critical. This property may prove very valuable depending on the type of project, especially if site accessibility is low. The long-term hardening behaviour of the unmodified bitumen is however not as dramatic as its short-term response, as the mixture only recovers to around $65 \%$ of its initial strength. Likewise, the $0.3 \%$ fibre content sample follows a parallel evolution within the short to long-term ageing period, indicating that if fibre inclusion is low enough, it will not prevent the impact of ageing during the service life. Under those conditions, small amounts of fibre may be used as a stiffness enhancer if there is a need for stronger pavements that require additional strength curing over time.

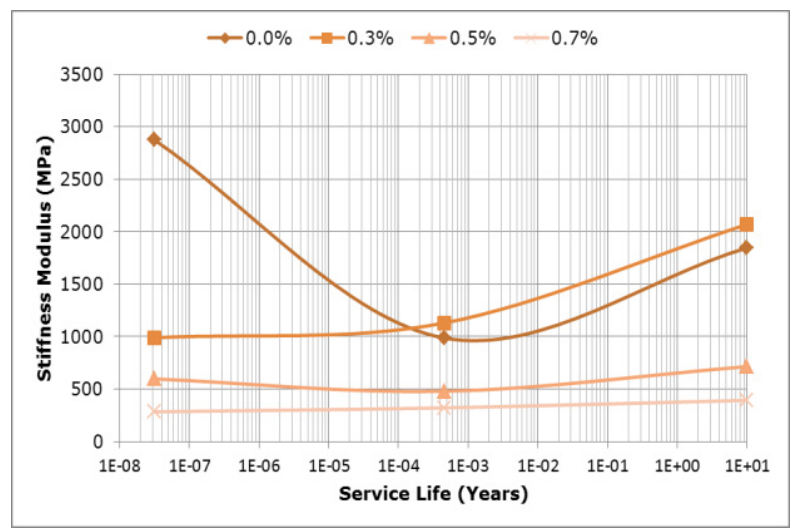

Fig. 4. Stiffness Modulus vs. Service Life

\subsection{Strain of stiffness modulus}

Fig. 5 shows the strain response of each sample expressed as a percentage of the strain in the other three samples. Hence, the largest bar of the chart reaches almost $190 \%$, meaning the strain value of the $0.5 \%$ sample represents almost $190 \%$ of the strain recorded for control sample, indicating that the $0.5 \%$ sample's deformation rate is nearly twice as high as that of an unmodified specimen. Similarly, there is a $47 \%$ increase in strain from the $0.0 \%$ to the $0.7 \%$ fibre content, suggesting high fibre modification is not suitable for high temperatures, because of the greater risk of permanent deformation and rutting to occur. In contrast, the strain difference between the unmodified and $0.3 \%$ content mixture remains relatively low as it only represents a $20 \%$ increase in strain rate, but this is still too 
unfavorable to justify fiber modification at high temperature, where high flexibility would also results in poor load spreading.

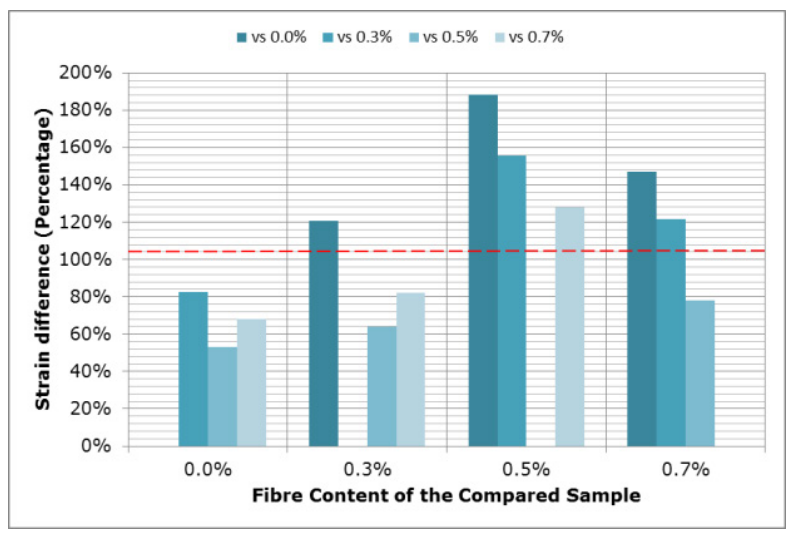

Fig. 5. Strain Response at different fiber content

\section{Conclusions}

Based on the results obtained, the fibre can yield both higher and lower stiffness at low temperature. Additionally, fibre also significantly reduces the impact of ageing on asphaltic mixture. The inclusion of fibre greatly reduces the effect of ageing in terms of stiffness gain or loss, especially from unaged to short-term. In this investigation, it is suggested to use coir fibre $\approx 0.4 \%$ (cold climates) and $\leq 0.3 \%$ (hot climates). This coir fibre modification not only provide the pavement with a high stiffness, but also with a better resistance to hardening over time, and therefore to cracking. This would give the pavement a much longer service life.

Research work presented in this paper was supported by Ministry of Higher Education Malaysia (MOHE) and Universiti Teknologi Malaysia (grant number Q.J130000.2522.18H05 and Q.J130000.2522.11H76). The financial assistance for this study is highly appreciated.

\section{References}

1. M. Safiuddin, M.Z. Jumaat, M.A. Salam, M.S. Islam, R. Hashim, Int. J. Phys. Sci. 05 (2010) 1952-1963.

2. $\quad$ M. Sivaraja, S. Kandasamy, Int. J. Mater. Prod. Tec. 36 (2009) 385-395.

3. M. Norhafizah, P.J. Ramadhansyah, J. Siti Nur Amiera, M. Nurfatin Aqeela, A.H. Norhidayah, M.R. Hainin, C.W. Che Norazman, J. Teknologi. 78 (2016) 127-132.

4. C.S. Bindu, K.S. Beena, Indian Coconut J. 52 (2009) 18-22.

5. T. Subramani, Int. J. Eng. Res. Appl. 02 (2012) 1794-1804.

6. $\quad$ K. Thulasirajan, V.L. Narasimha, Int. J. Earth. Sci. Eng. 04 (2011) 835-838.

7. T.L. Ting, R.P. Jaya, N.A. Hassan, H. Yaacob, D.S. Jayanti, M.A.M. Ariffin, J. Teknologi. 78 (2016) 85-89.

8. P.J Ramadhansyah, M. Nurfatin Aqeela, J. Siti Nur Amiera, M. Norhafizah, A.H. Norhidayah, S.J. Dewi, ARPN. J. Eng. Appl. Sci. 11 (2016) 7457-7462.

9. A. Kriker, G. Debicki, A. Bali, M.M. Khenfer, M. Chabannet, Cement Concrete Comp. 27 (2005) 554-564.

10. W. Shaopeng, Y. Qunshan, L. Ning, Constr. Build. Mater. 22 (2008) 2111-2115. 
11. C. Jianshiuh, L. Kueiyi, J. Mater. Sci. 40 (2005) 87-95.

12. Jabatan Kerja Raya, Standard and Specification for Road Works, Public Works Department (2008).

13. AASHTO R30-02, Standard Practice for Mixture Conditioning of Hot-Mix Asphalt (HMA), American Association of State and Highway Transportation Officials (2015).

14. ASTM D7369-11, Standard Test Method for Determining the Resilient Modulus of Bituminous Mixtures by Indirect Tension Test, Annual Book of ASTM Standards, West Conshohocken, Philadelphia, U.S.A (2011).

15. M.E. Abdullah, A.H. Madzaili, R.P. Jaya, H. Yaacob, N.A. Hassan, F.M. Nazri, IOP Conf. Series: Mater. Sci. Eng. 222 (2017) 1-5. 